\title{
Enkle spirometrimålinger i en generell mannlig befolkning
}

\author{
S. Humerfelt, G.E. Eide og A. Gulsvik \\ Lungeavdelingen, Haukeland Sykehus, Universititet i Bergen, 5021 Bergen \\ Korrespondanse til dr. Sjur Humerfelt \\ Telefon 55298060 calling 3226 Telefax 55975149
}

\begin{abstract}
SAMMENDRAG
Formålet var å evaluere deltagelsen ved enkle spirometrimålinger utført av menn fra den generelle befolkningen og å studere mulige prediktorer for ikke å oppnå godkjent test.

Alle menn i alderen 29-46 år bosatt i Hordaland fylke samt Sauda kommune $(\mathrm{N}=45380)$ ble invitert til en tverrsnittsundersøkelse i 1988-90. Luftveissymptomer, røykevaner og sivil status ble besvart via spørreskjema og målinger av forsert ekspiratorisk volum ved ett sekund $\left(\mathrm{FEV}_{1}\right)$ og forsert vital kapasitet (FVC) ble utført med Vitalograph belg-spirometre.

I alt deltok 29611 menn (65\%) i studien. Spirometrimålinger ble utført hos $91 \%$ av de fremmøtte og av disse var det kun $1,6 \%$ som ikke klarte å oppnå tre godkjente registreringer med $\leq 300 \mathrm{ml}$ mellom de to høyeste FVC verdiene. Andelen uten tre godkjente målinger var hyppigere hos aldri-røykere, ugifte og hos personer med luftveissymptomer enn hos hhv. røykere, gifte og asymptomatiske menn.

Konklusjon: Hos menn i alderen 29-46 år var risikoen for mislykket spirometri større hos aldri-røykere, ugifte og hos personer med luftveissymptomer enn hos hhv. røykere, gifte og asymptomatiske personer.
\end{abstract}

\section{Humerfelt S, Eide GE, Gulsvik A. Simple spirometry in a general male population. Nor J Epidemiol 1997; 7 (2): 243-248.}

\section{ENGLISH SUMMARY}

In this general population study we wanted to evaluate the participation of simple spirometry and to identify predictors of spirometric test failure.

All men aged 29-46 years living in western Norway $(\mathrm{N}=45,380)$ were invited to a cross sectional community survey. Respiratory symptoms, smoking habits and marital status were obtained from self-administered questionnaires and measurements of $\mathrm{FEV}_{1}$ and $\mathrm{FVC}$ were performed using dry-wedge bellow spirometers.

Altogether 29,611 subjects (65\%) participated in this survey. Spirometric recordings were obtained in $91 \%$ of the attendants $(n=26,803)$ of whom $1.6 \%$ failed the acceptability criterion of $\leq 300 \mathrm{ml}$ between the two highest of three FVC values. Spirometric failures were more prevalent in never smokers, single men and subjects with respiratory symptoms than in ever-smokers, married and asymptomatic subjects, respectively.

Conclusions: In men aged 29-46 years, spirometric test failures occurred more frequently in never smokers than in smokers and ex smokers after adjusting for other covariables. The higher failure rates observed in never smokers, in single men and in subjects with respiratory symptoms could be due to late compression of the airways and poor general health.

\section{INNLEDNING}

Standardiserte metoder er nødvendig for å oppnå best mulig validitet og minst mulig variabilitet ved målinger av den forserte ekspiratoriske manøver $(1,2)$. I følge retningslinjene fra den Europiske Kull- og Stålunion fra 1983 skal det ved godkjent test gjennomføres opp til åtte repeterte målinger for å oppnå minst tre godkjente målinger med en differanse $\leq 300 \mathrm{ml}$ mellom de to høyeste FVC-verdiene (1).

En rekke studier blant selekterte yrkesgrupper har funnet økt sykelighet og dødelighet hos personer uten tre godkjente spirometrimålinger $(3,4)$. Videre er det påvist større variabilitet i lungefunksjonen hos personer med obstruktiv lungesykdom enn hos friske personer (5). Disse sykdomsgruppene vil derfor ha 
større vanskeligheter med å oppnå godkjent test enn friske personer.

Fra generelle befolkninger foreligger det begrenset kunnskap om hvilke personer som ikke klarer å gjennomføre godkjente spirometrimålinger. I denne befolkningsundersøkelsen ønsket vi å evaluere deltagelsen ved spirometrimålinger blant menn i alderen 29-46 år og å studere mulige prediktorer for ikke å oppnå godkjent test.

\section{UTVALG OG METODE}

Alle menn i alderen 29-46 år bosatt i Hordaland fylke og Sauda kommune pr. 1. januar 1988 ble i 1988-90 invitert til en tverrsnittsundersøkelse (Støvlungeundersøkelsen) som ble gjennomført av Statens helseundersøkelser. En mobil enhet reiste rundt til hver kommune og utførte målinger av høyde, vekt, skjermbilde (6) og spirometri av alle de fremmøtte. Utfyllte spørreskjema med informasjon om røykevaner, yrkeseksposisjoner, luftveissymptomer og legediagnoser ble innlevert ved fremmøtet.

\section{Spirometri}

Målinger av forserte ekspirasjons-manøvre ble utført med tre Vitalograph belgspirometre (S-modell). Instrumentene ble kalibrert to ganger daglig (7). Målingene ble utført med personen sittende oppreist med neseklemme og en utåndingstid på minst 6 sekunder. Hver person utførte opp til åtte repeterte målinger inntil tre godkjente registreringer ble oppnådd med de to beste FVC-verdiene innen $300 \mathrm{ml}$ av hverandre $(1,2)$. De tre høyeste målingene av FVC og tilhørende $\mathrm{FEV}_{1}$ ble manuelt avlest til nærmeste $50 \mathrm{ml}$ av teknikeren. Denne kodet også antall godkjente målinger. Alle verdiene ble justert til kroppstemperatur og $760 \mathrm{~mm}$ Hg barometer trykk (BTPS-justering).

Tabell 1. Deltagelse og andel med spirometri mot alder, sivilstatus og bosted blant alle menn født i 1944-58 og bosatt i Hordaland fylke og Sauda kommune i 1988-90.

\begin{tabular}{|c|c|c|c|}
\hline & $\begin{array}{c}\text { Totalt } \\
\mathrm{N}\end{array}$ & $\begin{array}{c}\text { Fremmøtte } \\
(\mathrm{N}=29611) \\
\%\end{array}$ & $\begin{array}{l}\text { Fremmøtte } \\
\text { med spirometr } \\
(\mathrm{N}=26803) \\
\%\end{array}$ \\
\hline \multicolumn{4}{|l|}{ Alder: } \\
\hline 30-34 år & 12860 & 62 & 59 \\
\hline 35-39 år & 15135 & 65 & 60 \\
\hline 40-44 år & 15036 & 68 & 58 \\
\hline 45-46 år & 2333 & 67 & 60 \\
\hline \multicolumn{4}{|l|}{ Sivil status: } \\
\hline Ugift & 8710 & 57 & 53 \\
\hline Gift & 32572 & 70 & 63 \\
\hline Skilt/Separert & 3972 & 46 & 42 \\
\hline \multicolumn{4}{|l|}{ Bosted: } \\
\hline Landkommuner & 22392 & 73 & 63 \\
\hline Bergen by & 22988 & 58 & 56 \\
\hline Totalt antall & 45380 & 65 & 59 \\
\hline
\end{tabular}

I tillegg var det 16 menn med alderen 29 år.
Alders- og høydejusterte residualer av maksimum FEV $_{1}\left(\mathrm{SFEV}_{1}\right)$ og FVC (SFVC) ble benyttet som variabler for lungefunksjonsnivå (7). Disse ble beregnet ved å dividere det absolutte residual (differansen mellom maksimum og forventet verdi) med residualavviket fra regresjonsligningen hos den norske referansepopulasjonen av friske asymptomatiske menn (8).

\section{Statistisk analyse}

Analysene ble utført ved hjelp av programpakken BMDP (9). Uparrede t-tester ble benyttet for å sammenligne gjennomsnittsverdier, mens forskjeller i prevalenser ble testet ved hjelp av kji-kvadrat-teknikk. Et signifikansnivå på $\mathrm{p}=0,05$ (to-sidig) ble brukt $\mathrm{i}$ alle analysene. Multippel logistisk regresjonsanalyse ble benyttet for binære utfallsvariabler. Kategoriske variabler ble benyttet i analysene ved hjelp av "dummy" variabel teknikk.

\section{RESULTATER}

I alt deltok 29611 menn (65\% fremmøte) i studien (tabell 1). I tillegg returnerte 3\% (1301 menn) besvarte spørreskjema via posten. Fremmøtet var lavere i aldersgruppen $<35$ år enn hos dem $\geq 35$ år $(p<0,01)$, lavere hos ugifte/skilte/separerte enn hos gifte $(p<0,01)$ og lavere i Bergen by enn i landkommunene omkring $(\mathrm{p}<0,01)$ (tabell 1). Spirometri målinger ble utført hos $91 \%$ av de fremmøtte. Disse var noe yngre (mean (SD): 38 (4) år; $\mathrm{p}<0,01)$ enn fremmøtte uten spirometri (mean (SD): 40 (4) år). Begge grupper hadde identisk selvrapportert høyde, vekt, røykevaner og luftveissymptomer.

Kun 1,6\% av mennene klarte ikke å oppnå tre godkjente spirometrimålinger. Disse inkluderte personer med kun to $(n=187)$, en $(n=103)$ eller ingen $(\mathrm{n}=122)$ godkjente målinger (tabell 2). I tillegg var åtte ikke villig til å utføre undersøkelsen og femten andre hadde manglende verdier. Personer uten noen godkjente målinger var litt lavere (mean (SD): $176(7) \mathrm{cm}$ ) enn menn med tre, to eller en godkjent måling $(179(6) \mathrm{cm}$; $\mathrm{p}<0.001)$ og veide mindre (76 (13) $\mathrm{kg}$ ) enn de resterende (79 (11) kg; $\mathrm{p}<0.05)$.

Andelen av menn uten godkjent test var hyppigere hos aldri-røykere enn hos røykere og ex-røykere (tabell 2 og figur 1). Andelen røykere økte gradvis med antall godkjente målinger, fra $31 \%$ hos menn med ingen godkjente målinger til $44 \%$ hos menn med tre godkjente målinger (figur 1). Menn uten tre godkjente målinger bestod av en større andel ugifte $(p<0,001)$ (36\%) enn menn med tre godkjente målinger (17\%).

Andelen av menn med tung pust i motbakke og legediagnosen emfysem var høyere $(p<0,05)$ hos menn uten tre godkjente målinger enn hos dem med tre godkjente målinger (tabell 2). I alt rapporterte $48 \%$ ingen av de seks luftveissymptomene eller legediagnosene i tabell 2. Denne andelen økte gradvis med økende antall godkjente tester fra $38 \%$ hos dem uten 


\section{Antall godkjente spirometri målinger:}

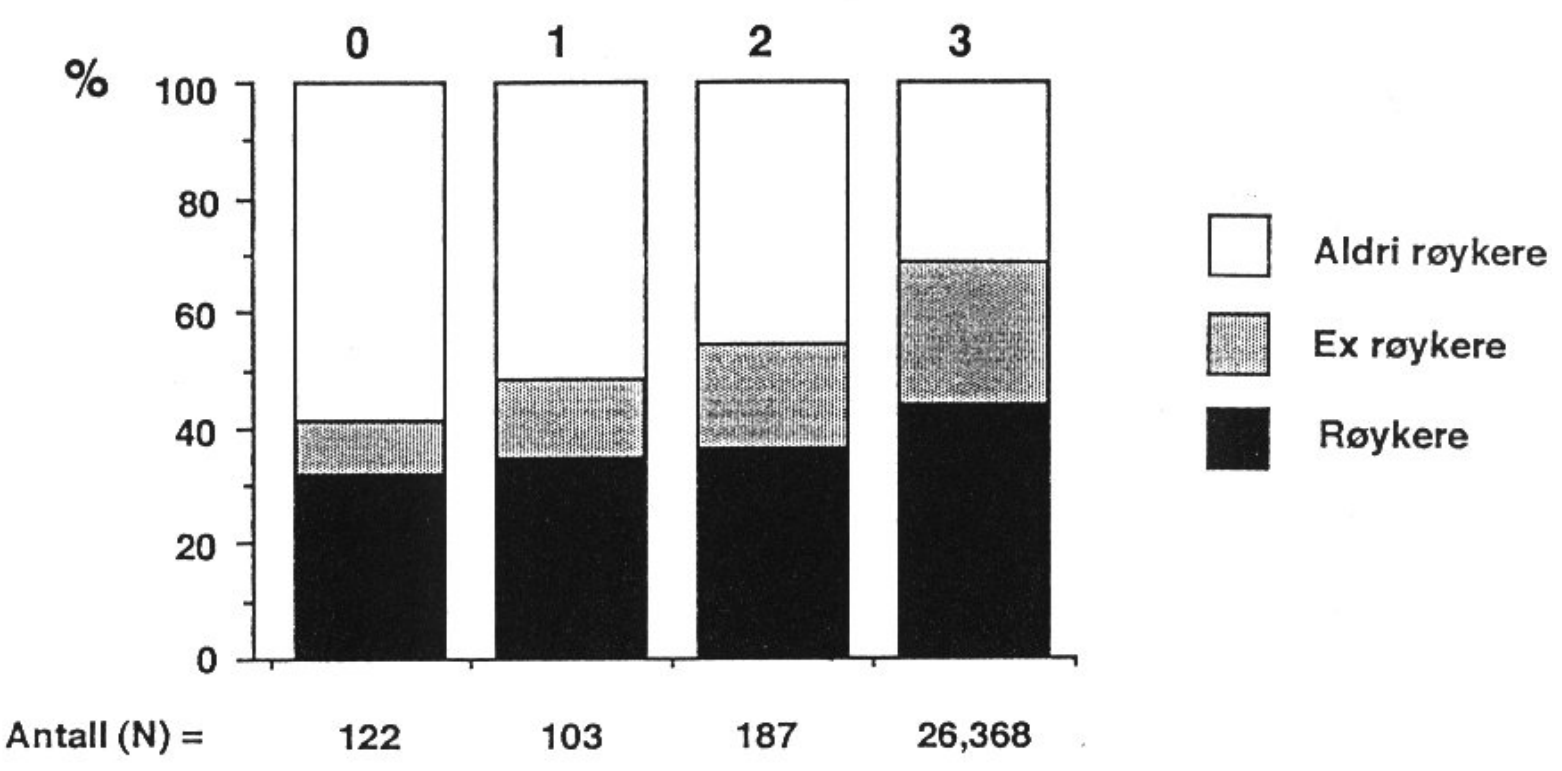

Figur 1: Røykevaner (\%) mot antall godkjente spirometrimålinger (n=26 780).

Tabell 2. Røykevaner, luftveissymptomer, legediagnoser og standardiserte residualer av $\mathrm{FEV}_{1}\left(\mathrm{SFEV}_{1}\right)$ og FVC (SFVC) mot antall godkjente spirometrimålinger.

\begin{tabular}{|c|c|c|c|c|c|}
\hline & Totalt & $\begin{array}{l}\text { Tre godkjente } \\
\text { målinger }\end{array}$ & $\begin{array}{l}\text { To godkjente } \\
\text { målinger }\end{array}$ & $\begin{array}{l}\text { En godkjent } \\
\text { måling }\end{array}$ & $\begin{array}{l}\text { Ingen godkjente } \\
\text { målinger }\end{array}$ \\
\hline$N(\%)=$ & $26803(100,0)$ & $26368(98,4)$ & $187(0,7)$ & $103(0,4)$ & $122(0,5)$ \\
\hline \multicolumn{6}{|l|}{ Roykevaner (\%): } \\
\hline Aldri røykere & 31,5 & $31,2 * *$ & 44,9 & 51,5 & 56,6 \\
\hline Ex røykere & 24,3 & 24,5 & 18,2 & 13,6 & 9,0 \\
\hline Røykere & 43,4 & 43,5 & 35,2 & 34,9 & 31,2 \\
\hline \multicolumn{6}{|l|}{ Luftveissymptomer (\%): } \\
\hline Morgenhoste & 10,0 & 10,0 & 7,2 & 17,5 & 9,6 \\
\hline Morgen oppspytt fra lungene & 9,6 & 9,6 & 9,6 & 8,0 & 17,3 \\
\hline Periodevis hoste/oppspytt $\geq 3 \mathrm{uk}$ & ker 21,6 & 21,6 & 19,6 & 22,7 & 27,0 \\
\hline Tungpusten i motbakke & 11,8 & $11,7 *$ & 9,9 & 17,3 & 23,2 \\
\hline Anfall av tung pust & 10,1 & 10,1 & 9,7 & 14,6 & 7,2 \\
\hline Piping & 19,4 & 19,5 & 16,2 & 20,0 & 11,6 \\
\hline \multicolumn{6}{|l|}{ Legediagnoser (\%): } \\
\hline Astma & 4,4 & 4,4 & 2,8 & 4,0 & 8,0 \\
\hline Emfysem & 0,1 & $0,1 *$ & - & 1,0 & 0,9 \\
\hline $\begin{array}{l}\text { Ingen av disse symptomene } \\
\text { eller legediagnosene }\end{array}$ & 48,4 & $48,5 * *$ & 46,0 & 39,8 & 37,7 \\
\hline $\mathrm{SFEV}_{1}$ mean $\pm \mathrm{SD}$ & $-0,44 \pm 0,95$ & $-0,44 \pm 0,95 * *$ & $-0,66 \pm 1,08$ & $-0,93 \pm 1,09$ & - \\
\hline $\mathrm{SFVC}$ mean $\pm \mathrm{SD}$ & $-0,20 \pm 0,95$ & $-0,20 \pm 0,94 * *$ & $-0,73 \pm 1,11$ & $-0,77 \pm 1,08$ & - \\
\hline
\end{tabular}

P-verdi for hver variabel ved sammenligning av deltagere med tre godkjente målinger mot resten: * $\mathrm{p}<0,05 \quad * * \mathrm{p}<0,01$ 
godkjente målinger til $49 \%$ hos dem med tre godkjente målinger. Menn uten tre godkjente målinger hadde lavere lungefunksjonsnivå enn dem med tre godkjente målinger (tabell 2).

Multippel logistisk regresjonsanalyse viste at risikoen for ikke å oppnå tre godkjente målinger var relatert til vekt, røykevaner og sivilstatus (tabell 3).

\section{DISKUSJON}

I denne tverrsnittsundersøkelsen blant menn i alderen 29-46 år var det meget høy deltagelse ved spirometrimålingene ( $91 \%$ av de fremmøtte). Det var kun 1,6\% som ikke klarte å oppnå kriteriet for godkjent test. Dette var hyppigere hos aldri-røykere, ugifte og hos menn med luftveissymptomer enn hos hhv. røykere, gifte og asymptomatiske menn.

Seleksjon ved fremmøtet kan ha påvirket disse resultatene. Derimot ble alle menn invitert til undersøkelsen og spirometri ble utført etter tur ved fremmøtet uavhengig av demografiske karakteristika eller svar gitt på spørreskjemaet. Forekomsten av røyking blant de fremmøtte var identisk til det som ble observert ved et postalt spørreskjema fra 1985 hos menn i alderen 30-45 år i det samme geografiske området (10). Røykespesifikke forekomster av de ulike luftveissymptomene i vår studie var i overensstemmelse med observasjoner fra et postspørreskjema i 1972 blant menn i alderen 30-49 år i Olso (11). Således er det usannsynlig at de observerte sammenhenger i vår studie kun skyldes seleksjonsskjevhet.

Gjenværende forstyrrende (confounding) effekter av røyking eller luftveissymptomer kan ha påvirket sammenhengen mellom sivilstatus og evnen til å gjennomføre godkjent spirometri. Dette kunne skje dersom røykevaner eller symptomer hos et individ ble rapportert ulikt hos ugifte sammenlignet med gifte menn. På den andre siden fant vi at sammenhengen var til stede også hos asymptomatiske aldri-røykere, noe som indikerer at en gjenværende forstyrrende effekt av røyking eller luftveissymptomer ikke kan forklare den observerte sammenheng.

Tabell 3. Spirometrimålinger i \% (N) med justerte ${ }^{+}$oddsratioer og $95 \%$ konfidensintervaller (K.I.) for ikke tre godkjente målinger mot alder, høyde, vekt, røykevaner og sivil status $(\mathrm{n}=24,826)$.

\begin{tabular}{|c|c|c|c|c|c|}
\hline \multirow[b]{2}{*}{ Faktor: } & \multirow{2}{*}{$\frac{\text { Totalt }}{\mathrm{N}}$} & \multicolumn{4}{|c|}{ Ikke tre godkjente spirometrimålinger } \\
\hline & & $\%$ & $\mathrm{~N}$ & Odds ratio & $95 \%$ K.I. + \\
\hline \multicolumn{6}{|l|}{ Alder: } \\
\hline 30-34 år & 6849 & 1,7 & 115 & 1 & \\
\hline 35-39 år & 8402 & 1,5 & 129 & 1,1 & $0,9-1,4$ \\
\hline 40-44 år & 8264 & 1,5 & 122 & 1,2 & $0,9-1,5$ \\
\hline 45-46 år & 1311 & 1,8 & 23 & 1,4 & $0,9-2,3$ \\
\hline \multicolumn{6}{|l|}{ Hoyde: } \\
\hline$<175 \mathrm{~cm}$ & 6405 & 1,7 & 112 & 1 & \\
\hline $175-179 \mathrm{~cm}$ & 7551 & 1,4 & 107 & 0,9 & $0,7-1,2$ \\
\hline $180-184 \mathrm{~cm}$ & 7050 & 1,6 & 111 & 1,0 & $0,7-1,3$ \\
\hline$\geq 185 \mathrm{~cm}$ & 3820 & 1,5 & 59 & 0,9 & $0,7-1,3$ \\
\hline \multicolumn{6}{|l|}{ Vekt: } \\
\hline$<70 \mathrm{~kg}$ & 4908 & 2,0 & 98 & 1 & * \\
\hline $70-79 \mathrm{~kg}$ & 9347 & 1,3 & 120 & 0,7 & $0,5-0,9$ \\
\hline $80-89 \mathrm{~kg}$ & 6860 & 1,7 & 114 & 0,9 & $0,7-1,2$ \\
\hline$\geq 90 \mathrm{~kg}$ & 3711 & 1,5 & 57 & 0,8 & $0,6-1,2$ \\
\hline \multicolumn{6}{|l|}{ Roykevaner: } \\
\hline Aldri røykere & 7889 & 2,6 & 202 & 1 & $*$ \\
\hline Ex røykere & 6096 & 1,0 & 60 & 0,4 & $0,3-0,6$ \\
\hline Røyker $<15$ sig/dag & 4700 & 1,2 & 58 & 0,5 & $0,4-0,7$ \\
\hline Røyker $\geq 15$ sig/dag & 6141 & 1,1 & 69 & 0,5 & $0,3-0,6$ \\
\hline \multicolumn{6}{|l|}{ Sivil status: } \\
\hline Gift & 18997 & 1,2 & 231 & 1 & $*$ \\
\hline Ugift & 4258 & 3,4 & 144 & 2,7 & $2,1-3,3$ \\
\hline Skilt/Separert & 1571 & 0,9 & 14 & 0,8 & $0,5-1,4$ \\
\hline
\end{tabular}

+ Justert for alder, høyde, vekt, røyking og sivil status.

\$ Statistisk signifikans for den uavhengige variabel i modellen for ikke tre godkjente målinger: $* \mathrm{p}<0,05 \quad * * \mathrm{p}<0,01$. 
Det lavere fremmøtet hos ugifte menn i denne studien kan indikere at ugifte var mindre motiverte til å utføre spirometri enn gifte menn. Status som ugift kan også være en indikator på sykelighet (12) og representere en markør for en annen korrelert faktor, slik som lav sosioøkonomisk status eller lav inntekt (13). Vi bør derfor tolke sammenhengen mellom sivilstatus og evnen til å oppnå godkjent test med forsiktighet siden andelen ikke-fremmøtte var høyere hos ugifte enn hos gifte menn.

I likhet med tidligere studier både fra selekterte yrkesgrupper $(3,4)$ og generelle befolkninger (14) fant vi at godkjent spirometri var hyppigere hos friske enn hos symptomatiske menn etter å ha justert for røyking, sivilstatus og alder.

Tidligere studier har funnet ulike sammenhenger mellom røyking og evnen til godkjente spirometrimålinger $(4,14,15)$. Forskjeller i utvalg, alder, røykevaner og forekomsten av obstruktiv lungesykdom kan muligens forklare noen av disse forskjeller. Vi fant at godkjent spirometri var hyppigere hos røykere og exrøykere enn hos aldri-røykere etter å ha justert for de andre kovariablene. Seleksjonsskjevhet kan være en forklaring på dette. Personer med bronkial hyperreaktivitet vil kanskje ikke starte å røyke og røykere som utvikler bronkial hyperreaktivitet vil tendere til å slutte å røyke (16). En annen mulig forklaring kan være at maksimal utåndings hastighet oppnås ved et lavere intrapleuralt trykk hos personer med luftstrømsobstruksjon grunnet kompresjon av luftveiene $(17,18)$. Dette vil medføre mer reproduserbare målinger hos røykere enn hos aldri-røykere. Til støtte for denne hypotesen fant vi mindre gjennomsnittlig standardavvik innen individet $\mathrm{i}$ de tre spirometrimålingene hos røykere enn hos aldri-røykere (19).

\section{ANERKJENNELSE}

Vi vil gjerne takke ansatte ved Statens helseundersøkelser for utmerket arbeid med datainnsamling, punching og utarbeidelse av analysefil. Vi vil også takke Steinar Nilssen ved Senter for Medisinsk Informatikk og Statistikk, Universitetet i Bergen, for teknisk assistanse. Arbeidet er støttet økonomisk fra Norges Forskningsråd, J. E. Isbergs fond og NHOs Arbeidsmiljøfond.

\section{REFERANSER}

1. Quanjer PH. Standardized lung function testing. Bull Eur Physiopathol Respir 1983; 19 (Suppl 5): 7-10.

2. American Thoracic Society. Standardization of spirometry: 1987 update. Am Rev Respir Dis 1987; 136: 12851298.

3. Eisen EA, Oliver LC, Christiani DC, Robins JM, Wegman DH. Effects of spirometry standards in two occupational cohorts. Am Rev Respir Dis 1985; 132: 120-124.

4. Kellie SE, Attfield MD, Hankinson JL, Castellan RM. Spirometry variability criteria - association with respiratory morbidity and mortality in a cohort of coal miners. Am J Epidemiol 1987; 125: 437-444.

5. Pennock BE, Rogers RM, McCaffree DR. Changes in measured spirometric indices - what is significant? Chest 1981; 80: 97-99.

6. Bjartveit K, Foss OP, Gjervig T, Lund-Larsen PG. The cardiovascular disease study in Norwegian counties. Background and organization. Acta Med Scand Suppl 1979; 634: 5-70.

7. Humerfelt S, Gulsvik A, Skjærven R, Nilssen S, Kvåle G, Sulheim O, et al. Decline in FEV 1 and airflow limitation related to occupational exposures in men of an urban community. Eur Respir J 1993; 6: 1095-1103.

8. Gulsvik A. Prevalence and manifestations of obstructive lung disease in the city of Oslo. Scand J Respir Dis 1979; 60: 286-296.

9. Dixon JW, editor. BMDP Statistical Software Manual. Berkeley: University of California Press, 1990.

10. Bakke P, Gulsvik A, Eide GE, Hanoa R. Smoking habits and lifetime occupational exposure to gases or dusts, including asbestos and quartz, in a Norwegian community. Scand J Work Environ Health 1990; 16: 195-202.

11. Gulsvik A. Prevalence of respiratory symptoms in the city of Oslo. Scand J Respir Dis 1979; 60: $275-285$.

12. Jacobsen BK, Thelle DS. The Tromsø Heart Study: responders and non-responders to a health questionnaire, do they differ? Scand J Soc Med 1988; 16: 101-104.

13. Tibblin G. A population study of 50-year-old men: an analysis of the non-participation group. Acta Med Scand 1965; 178: 453-459.

14. Eisen EA, Dockery DW, Speizer FE, Fay ME, Ferris BG. The association between health status and the performance of excessively variable spirometry tests in a population-based study in six US cities. Am Rev Respir Dis 1987; 136: 1371-1376. 
15. Nganga LW, Ernst P, Jaakkola MS, Gerardi G, Hanley JH, Becklake MR. Spirometric lung function. Distribution and determinants of test failure in a young adult population. Am Rev Respir Dis 1992; 145: 48-52.

16. Bakke P, Baste V, Gulsvik A. Bronchial responsiveness in a Norwegian community. Am Rev Respir Dis 1991; 143: $317-322$.

17. Hyatt RE, Flath RE. Relationship of air flow to pressure during maximal respiratory effort in man. $J$ Appl Physiol 1966; 21 (2): 477-482.

18. Davies C, Campbell EJM, Openshaw P, Pride NB, Woodroof G. Importance of airway closure in limiting maximal expiration in normal man. J Appl Physiol 1980; 48: 695-701.

19. Humerfelt S, Eide GE, Kvåle G, Gulsvik A. Predictors of spirometric test failure: a comparison of the 1983 and 1993 acceptability criteria from the European Community for Coal and Steel. Occup Environ Med 1995; 52: 547-553. 